\title{
Freeing Up Time
}

\author{
ROBERT E. GOODIN \\ Australian National University
}

\begin{abstract}
Increasing people's control over how they spend their time is a worthy ambition. But there is only so much we will be able to do in that regard. It is important to conceptualize discretionary time in a measurable way in order to appreciate both the potential and the limits of standard policies designed to do that.
\end{abstract}

Keywords: discretionary time; free time; temporal autonomy

\section{PUTTING THINGS INTO PERSPECTIVE}

It is sometimes said that time is the most equally distributed resource in the world. Everyone, everywhere has exactly 24 hours in their day - no more, no less. But that is a cruel joke in all sorts of ways.

Perhaps the most important is this. Some people live longer than others. While everyone has only the same 24 hours in the day for as long as they live, some people have many more cumulative hours in their lifetimes. And given what we now know about the "social determinants of health", there is clearly something we can do about that, even apart from finding miracle cures for nasty diseases (Wilkinson and Marmot 2003; WHO 2008; Wilkinson and Pickett 2009). Equalizing people's other resources would clearly help equalize their hours, from a whole-life perspective.

Here is another way that the equality of clock-time is a cruel joke. Some people own other people's time (in relations of slavery) or rent it (via the employment relationship). Slave owners and employers gain, and slaves and employees lose, control over time. Slavery has been everywhere (officially) abolished. But until we overcome the necessity for the vast majority of people to rent their time to employers simply in order to survive, there will be gross inequality in the amount of time over which different people have control. ${ }^{1}$ Universal Basic Income, paid at a rate that would

1 In pre-industrial societies (Thompson 1967), and in post-productivist ones (Goodin 2001), people have more control over their time. 
make abstaining from paid employment a viable option, would solve that problem - but while important experiments with that are underway, full implementation of that on a scale anything like adequate to that task is a long way off (Widerquist et al. 2013; Van Parijs and Vanderborght 2017). ${ }^{2}$

A third way the seeming equality of clock-time is a cruel joke has to do with differential access to technology. From a time-use perspective, the greatest boon to women's lives was arguably the introduction of the electric washing machine (Gershuny and Robinson 1988; Gershuny 2000: 67). Technological innovations allow us to accomplish the same tasks in less time. Those with access to those technologies are temporally advantaged; those without it are temporally handicapped. That is another source of temporal inequalities, whatever the apparent equality of clock-time might suggest.

Finally, there are the temporal inequalities that arise from people's own life choices. Those choices are not, in the first instance anyway, choices about how to use their time - they are instead choices about other things that have temporal implications (appreciated or not, at the time of making the choice). In Discretionary Time my coauthors and I (semi)jokingly concluded that, "To maximize temporal autonomy and discretionary time, people should:

- marry but never have children;

- if they do have children, never divorce; and

- maybe consider moving to Sweden" (Goodin et al. 2008: 263).

Of those three, the first two are much the most important. Caring for children is hugely time-consuming, particularly as a lone parent. No one who wishes the species to persist (or even just their pension to be paid) would wish people not to have children. But gross temporal inequalities arise between people who do and do not (or cannot) procreate, and the capacity of public policy to mitigate those disparities is strictly limited.

Those are hard facts about temporal autonomy and inequality, against which this discussion must be set. If you really want to be a temporal egalitarian, or if you really want to maximize people's control over the way they use their time, there are many more important things to be talking about than conventionally cluster under the heading of "time use" or "work-life balance" policies.

The focus of discussion here will inevitably be on what contributions

2 Of course basic income in any amount would reduce, if not eliminate, the time people have to spend in paid labor to meet their basic needs - and more so for those on low wage rates who would otherwise have to work longer hours to earn the same amount. 
of a more limited sort public policy might make to people's discretionary control over the way they use their time, and the benefits they derive from so doing (the "Swedish" point, above). But let us go into that discussion with our eyes wide open to the strictly limited scope of that discussion. Were we serious about temporal autonomy and its equality, and had we power to change the world in more radical ways, there would be other far more important priorities.

\section{WHAT TEMPORAL AUTONOMY IS NOT}

Julie Rose (2016) is right to focus her book on "free time". Strictly speaking, that is a misnomer in terms of the standard time-use coding conventions. ${ }^{3}$ But it is nonetheless clear what Rose (2016: 4) wants, which is that we be guaranteed "hours for what we will". That is "discretionary time" in our book of that title (Goodin et al. 2008). It is the time over which one has discretionary control, the time that is left over after discharging all of life's necessities in various dimensions. That is the time over which one enjoys "temporal autonomy".

There are two important things to notice about discretionary time, right from the start. The first is that people will often choose to spend some (yea, much) of it doing more-than-is-strictly-necessary in those very same dimensions. If the poverty line defines a minimum necessary income, then the time it takes you to earn a poverty-level income at your wage rate is your "necessary time in paid labor". But, quite reasonably, most of us are not content with a poverty level income, and we spend much more time in paid labor than strictly required just to earn just a poverty-level income. Ditto cooking and cleaning and caring for the kids. It is perfectly reasonable (indeed, wholly laudatory) that people should spend more of their time in each of those activities, too, than is minimally necessary. The point is merely that, when people spend more time in those activities than strictly is necessary, that should be seen as a choice of how to allocate their discretionary time. It would be a huge mistake to think that people are

3 In standard time-use terminology, "free time" is time not actually spent in necessary activities of life (paid labor, unpaid household labor, personal care) (UN 2005: 193). But however "necessary" the activities (sleeping, etc.) may themselves be, people can - and typically do (more on which below) - spend far more time than strictly necessary engaged in them. Hence what time-use researchers conventionally call "free time" might better be dubbed "spare time" (Goodin et al. 2008: 51-2; Rose 2016: 59). "Leisure time" is time spent in specific leisure activities (sport, watching television, or whatever). Not all free (spare) time is spent in any of those specific leisure activities.

4 Although, as I shall go on to argue, "temporal autonomy" involves other considerations as well, including those of when you do what, and how much control you have over how you discharge those tasks. 
enjoying discretionary time only when they are engaging in what would conventionally be called "leisure activities" (playing sports, or going to the cinema, or whatever).

The second crucial thing to note is that "free" or "discretionary time" speaks to the value of "temporal autonomy". That is not conceptually distinct from the "equality of temporal autonomy". ${ }^{5}$ Whether or not what maximizes temporal autonomy also equalizes it across society as a whole is purely an empirical question. As it happens, it seems that households that practice temporally inegalitarian divisions of labor also have (across the household taken as a whole) less discretionary time as well. ${ }^{6}$ But that is purely a contingent matter, an empirical truth rather than an analytic one.

\section{EMPIRICS MATTER}

Rose eschews empirical measures of discretionary time. Indeed, her philosophically preferred conceptualization of "free time" in terms of how much time it takes each individual to meet "basic needs" in his or her own very particular circumstances would almost certainly defy any attempt at systematic empirical operationalization (2016: 55-7). Rose (2016: 57) concedes as much when weakening her recommendation as I shall discuss shortly.

In Discretionary Time, we employ a "social benchmark" operationalization modelled on the standard conceptualization of the poverty line (Goodin et al. 2008: 34-53). As such, ours is a socially relative measure. Rose (2016: 55) complains that that fact renders it "potentially responsive to spurious social factors" - "individuals ... might, due to competitive pressures or other social norms, spend either more time or less time than is objectively necessary" in any given activity. True, but the standard measure of "poverty" (as having less than half the median equivalent income among people in your country [Atkinson 1998]) is relative in just the same way and for good reason (Townsend 1979). Rose (2016:55) further complains that our measure takes no account of the extra time disabled people may need to perform the same tasks as others. But neither, of

5 While Rose (2016: 128-34) officially leaves the choice of distributive rule open, when she calls for everyone to have a "fair share of free time" it is clear that that would be a more egalitarian distribution than at present. Here and in what follows, you can substitute for "egalitarian" any of those other distributive rules that Rose envisages and the same basic point would remain.

6 Across the eight countries studied in Goodin et al. (2008: 229), an "Equal Temporal Contribution" division of household labor gives a household an hour or two more discretionary time on average than inegalitarian "Male Breadwinner" or "Most-efficient Breadwinner" divisions of household labor. 
course, do conventional poverty measures take any account of the extra money that disabled people need to perform the same tasks as others. So we are in good company, and I shall go on to argue for good reason.

Conceding the empirical inscrutability of her philosophically preferred conceptualization of free time, Rose (2016:57) proposes for the purposes of a public standard of justice a measure of free time that is only "moderately tailored to relevant individual circumstances" ${ }^{7}$ By that she means it should take into account, not how much time it would take any particular actual individual to perform a necessary task, but rather how long "is objectively necessary for individuals in a set of relevant circumstances", such as a particular class of disability. Given a suitable data set, a "social benchmark" akin to ours in Discretionary Time could indeed be constructed for people with each specific class of disability. However, notice that that measure itself would elide individual differences among persons within the same broad disability class, in just the same way (merely to a lesser extent) that Rose complains about in our original measure of discretionary time.

Furthermore, that added granularity would come at a cost. Public policy inevitably, and from a rule-of-law perspective rightly, operates through a system of rules that are general in form (Goodin 1995: ch. 1). For policy purposes, special needs such as those of the disabled are better seen as "exceptional circumstances" to be addressed separately, perhaps sometimes even on a purely case-by-case basis. Likewise when compiling social statistics to inform policy, it is better to employ whatever indicators best reflect the situation of the general population as a whole. That is what should inform general policy. It would be quite wrong to let general social policy, or social statistics either, be unduly driven by the need to accommodate the very special circumstances of some small and very special (however sympathetic) subgroups of the population.

The advantage of using the "social benchmark" standard that we developed in Discretionary Time is that it allows us to calibrate relative effects of different social circumstances and policy interventions on people's temporal autonomy. Using that measure, it becomes clear just how great are the temporal inequalities between single parents and others - and just how great those are likely to remain even with Swedish-quality support and workplace accommodation.

Here is the crucial calculation. In the US, people in childless dualearner households have around 94 hours per week of discretionary time,

7 As Rose (2016: 46-7; cf. 87) acknowledges, in order for it to play a role in a public theory of justice, we need a concept of free time such "that it is possible to reliably and verifiably know whether an individual possesses" a given amount of it or not. 
compared to 51 hours of discretionary time for US single parents. In Sweden, the figure is 95 hours per week for childless dual-earners but 70 hours a week for single parents (Goodin et al. 2008: 64). Clearly, single parents have massively more temporal autonomy in Sweden than in the US. Equally clearly, they are still massively worse off than childless dualearners, even in Sweden. That is simply to say that there is only so much that even the very best social policy interventions can do in this realm.

\section{REDUCING VERSUS REDISTRIBUTING TIME IN NECESSARY TASKS}

As my earlier allusion to the electric washing machine indicates, technological innovations can sometimes reduce the total number of hours that anyone has to spend in necessary tasks of life. ${ }^{8}$ An electric washing machine yields equally clean clothes with far fewer temporal inputs. Telecommuting - working from home via the internet - cuts out time that would otherwise be required to travel to work. And so on.

Just occasionally, time-use policies designed to improve the work-life balance work in similar fashion. Much more commonly, they simply redistribute the necessary tasks. Child care is a prime example. Social policymakers reduce (in some places much more than in others) the time pressure on parents through a suite of taxes-and-transfers and child care subsidies, in effect "buying them out" of necessary time in child care (Goodin et al. 2008: 177-96). But these policies do little to reduce society's total amount of time spent on child care ${ }^{9}$ The kids still have to be taken care of by someone. What these policies primarily do is redistribute child care time from one person (the parent) to another (the employed child carer), in the process transforming the one's "necessary time in unpaid household labor" into someone else's "time in paid labor".

Make no mistake: that may be a very good thing in all sorts of ways. Assuming the parents are glad for the extra time and the child carer is glad for the extra money, it can be a mutually beneficial trade much to be welcomed - at least if the child carer gets paid a decent, non-exploitative wage. Socially, too, there may be something to be said for sharing around responsibility for the care of society's children.

Butlet us seeit clearly for what it principally is: essentially a redistribution

8 Rose (2016: 128) alludes, in similar spirit, to variability in "how much time a society [as a whole] must devote" to necessary tasks.

9 Except insofar as they increase multi-tasking, with childcare workers minding more children at the same time. 
rather than a genuine reduction of temporal burdens across the society as a whole. ${ }^{10}$ Statisticians quip that if all married men divorced their wives and hired them back as housekeepers the National Income would double (Clark 1958). Let us not fall for a similar sleight of hand, here, mistaking a change in coding categories for a real overall reduction.

\section{TIME SHIFTING AND HARMONIZATION}

Much the same can be said about Rose's (2016: 112-26) proffered "workplace accommodation" policies for easing the temporal burdens on parents. Insofar as that merely amounts to letting parents attend to child-related duties during working hours, and making up that lost time to their employers at some other time, parents would experience no net gain in free time as a result. They would gain more discretionary control over when they do what they have to do - and of course that is a genuinely important dimension of temporal autonomy in its own right. But that is not to be confused with giving parents their "fair share of free time", as Rose often puts it. Time-shifting leaves the sum-total of one's temporal commitments completely unchanged.

Discretionary control over when to do what one has to do is important in all sorts of ways. It is the difference between working on a production line and "being one's own boss". It is the difference between working to a "roster" and being perpetually "on call". It is crucial for being reliably able to coordinate time to share with partners and friends.

Flexitime works fine for that, when you are just trying to coordinate with one or a few others. It works less well when there are many others with whom you are trying to coordinate, particularly for different purposes. Rose (2016: 99-101) advocates Sunday closing legislation on the grounds that they are a means of orchestrating "shared free time" across the entire society.

Rose describes a common period of free time across the entire society as being necessary to ensure "freedom of association". Associations are affinity groups. Rose (2016: 101) mentions, as examples, associations among people united in a political cause, a religious practice, a family or a social network. Here, we are talking about people getting together with

10 Note that with paid child care of any form, someone has to spend time in paid labor to pay for it as well as someone paid for the purpose having to spend time taking care of the children. (Funding child care through progressive taxes minimizes the former factor but hardly eliminates it.) The sum of those two factors will almost certainly exceed the time that would have been necessary if the children were cared for through unpaid household labor. 
others with whom they antecedently know they have something in common.

Even more important might be the way in which a period of common free time might facilitate people unintentionally bumping into others with whom they have no prior acquaintance and nothing knowingly in common. Extreme social segmentation, combined with the hyperpolarization that it breeds, is bad for a society. There is surely a strong case to be made for "random sorting", and for a common period of free time across the entire society to facilitate that - just as in earlier periods there was a case to be made for public parks as places that people otherwise segregated by class and ever so many other dimensions of social difference could brush up against one another and, with luck, come to see one another as fellows (Sunstein 2001: 23-50). As that example suggests, however, a period of common free time is not enough to ensure social mixing - common public spaces are required as well.

\section{AUTONOMY IN (AND NOT JUST OVER) TIME USE}

If we care about people's autonomous control over their time, then we should (as I have said) care about their autonomous control over when they do what they have to do, as well as over how much time they spend doing it. A concern with people's autonomous control over their time should also lead us to care about how much control they have over what they are doing, whether they are engaging in that activity out of choice or necessity.

That is true across the range of possible uses of their time. People need to spend a certain amount of time (and typically choose to spend still more) cooking and grooming and raising their kids. Autonomy is served by their having a choice whether or not to spend extra time in those ways. But autonomy is also served by their having more than just one choice (or any small number of choices) in what to cook, how to groom and how to raise their kids. That is one of the standard things said in praise of liberal societies in general.

Something analogous is importantly true as regards time spent in paid labor. Across the eight countries we studied, people of prime working age spend on average around 38 hours in paid labor, around half of that out of choice and half out of necessity (Goodin et al. 2008: 88). If we care about people's autonomy, we should surely care not merely about their autonomy in choosing whether, when and how long to work - important though those choices obviously are. We should also care about the degree of autonomy that people are able to exercise in doing the work that they do (Muirhead 2004). Opportunities to exercise autonomous choice within the workplace 
are as important as opportunities to exercise autonomy in how much time to spend at work.

\section{WELFARE IS SOMETHING ELSE YET AGAIN}

Finally, recall that autonomy is one thing, welfare another. The two may be contingently connected. Indeed, they typically are. Having a choice enables you to get what you want, making you (subjectively, anyway) better off in consequence. However strongly that contingent connection, however, autonomy and welfare are nowise identical.

Time and discretionary control over it is a resource. However, how much "good" one derives from that resource depends on how one uses that resource. Poverty researchers say the same thing about money: a miser with a lot of money in the bank is resource-rich, even if (because he refuses to spend any of it) he is welfare-poor (Ringen 1988).

Ensuring that people have adequate (or equal) resources - whether of free time or other sorts - can be a socially important goal in and of itself. It enhances their autonomy. It equalizes their opportunities. But we should not fool ourselves into thinking that ensuring adequate or even equal temporal autonomy to everyone will necessarily lead to equality of welfare, to equality in the quality of their lives.

\section{BIBLIOGRAPHY}

Atkinson, A.B., 1998: Poverty in Europe, Oxford: Blackwell.

Clark, C., 1958: “The Economics of Housework", Bulletin of the Oxford Institute of Statistics 20: 205-11.

Gershuny, J., 2000: Changing Times, Oxford: Oxford University Press.

Gershuny, J. and J.P. Robinson, 1988: "Historical Changes in the Household Division of Labor", Demography, 25: 537-52.

Goodin, R.E., 1995: Utilitarianism as a Public Philosophy, Cambridge: Cambridge University Press.

-2001: "Work and Welfare: Toward a Post-Productivist Welfare State", British Journal of Political Science 31: 13-40.

Goodin, R.E., J.M. Rice, A. Parpo and L. Eriksson, 2008: Discretionary Time: A New Measure of Freedom, Cambridge: Cambridge University Press.

Muirhead, R., 2004: Just Work, Cambridge: Harvard University Press.

Ringen, S., 1988: “Direct and Indirect Measures of Poverty", Journal of Social Policy 17: 351-65.

Rose, J.L. 2016: Free Time, Princeton: Princeton University Press.

Sunstein, C., 2001: Republic.Com, Princeton: Princeton University Press. 
Thompson, E.P., 1967: “Time, Work Discipline and Industrial Capitalism”, Past \& Present 38: 56-97.

Townsend, P., 1979: Poverty in the United Kingdom, Harmondsworth: Penguin.

United Nations (UN), Department of Economic and Social Affairs, Statistics Division, 2005: Guide to Producing Statistics on Time Use, New York: United Nations.

Van Parijs, P. and Y. Vanderborght, 2017: Basic Income, Cambridge: Harvard University Press.

Widerquist, K., J.A. Noguera, Y. Vanderborght and J. De Wispelaere, eds, 2013: Basic Income, Malden: Wiley Blackwell.

Wilkinson, R. and M. Marmot, eds, 2003: Social Determinants of Health: The Solid Facts, $2^{\text {nd }}$ edition, Copenhagen: WHO.

Wilkinson, R.G. and K. Pickett, 2009: The Spirit Level: Why More Equal Societies Almost Always Do Better, Harmondsworth: Penguin.

World Health Organisation (WHO), 2008: Closing the Gap in a Generation: Health Equity through Action on the Social Determinants of Health, Final Report of the Commission on Social Determinants of Health, Geneva: WHO. 